\title{
The Ethics of Terraforming: A Critical Survey of Six Arguments
}

Ian Stoner

Department of Philosophy, Saint Paul College, Saint Paul, MN, USA

\begin{abstract}
If we had the ability to terraform Mars, would it be morally permissible to do it? This article surveys three preservationist arguments for the conclusion that we should not terraform Mars and three interventionist arguments that we should. The preservationist arguments appeal to a duty to conserve objects of special scientific value, a duty to preserve special wilderness areas, and a duty not to display vices characteristic of past colonial endeavors on Earth. The interventionist arguments appeal to a duty to fulfill our pioneering nature, a duty to extend the lifespan of our species, and a duty to restore the ecosystems Mars may once have housed. The preservationist arguments are stronger than the interventionist arguments; terraforming Mars is probably morally wrong.
\end{abstract}

Keywords: Environmental ethics, Mars colonies, practical ethics, space colonization, space ethics, terraforming

What shall we do with Mars? There are so many examples of human misuse of the Earth that even phrasing this question chills me.

-Carl Sagan, Cosmos

\subsection{Introduction}

We already possess technology that would allow us to effect unpredictable changes to the Martian environment. At some point in the future, we may develop technologies that will allow us to reshape Mars's climate to be more hospitable to us. Most of the other papers in this book focus on the science and engineering of terraforming; this one focuses on evaluating that goal. Should we terraform Mars?

This is an ethical question, a philosophical question. Although people enthusiastic about terraforming sometimes overlook it, they shouldn't; the question of the moral permissibility of terraforming Mars is a philosophical question that emerges from experiences of nature that nearly everyone on Earth has had.

For example, my first visit to the gypsum dunefield in White Sands National Park in New Mexico left me dazzled. After a short hike in I found myself embedded in a stark, lifeless,

Email:ian.stoner@saintpaul.edu

Martin Beech, Joseph Seckbach, and Richard Gordon (eds.) Terraforming Mars, (101-116) @ 2022 Scrivener Publishing LLC 
seemingly endless expanse. Somehow, it looked simultaneously exactly like and nothing like a rolling Midwestern countryside after a heavy snow. My environment's palette contracted to two colors: the brilliant whites of sand and cloud, and the many blues of the sky. White Sands is beautiful, sterile, vast, and humbling. "Terraforming" its sublime austerity to make it more hospitable to humans or more economically productive strikes me as clearly a wrongful abuse of that land, even though it is not immediately clear to me how to articulate why it would be wrong.

Kim Stanley Robinson, author of the Mars trilogy of terraforming novels, speaks similarly of his own favorite hostile environment: "If somebody proposed irrigating and putting forests in Death Valley, I would think of this as a travesty" [6.1]. Like me, like Robinson, you probably have a favorite stretch of arid, or barren, or hostile land that you would fight to preserve from irrigation or other large-scale intervention undertaken under the guise of greening.

If there is a hostile environment on Earth that you believe would be wrong to green, then you believe it is possible to treat land wrongfully by greening it. Is Mars such land? Or is it the sort of land it is morally permissible to terraform?

In this paper I summarize and evaluate six arguments about the moral permissibility of terraforming Mars. I conclude that the most prominent arguments in favor of terraforming have significant weaknesses and the arguments against terraforming are plausible. Terraforming Mars is probably something we should not do.

\subsection{Audience and Method}

I take my audience to be primarily scientists, engineers, and students interested in terraforming, as well as philosophers new to this niche ethical debate. I will therefore present arguments, and highlight their strengths and weaknesses, assuming no background in philosophy.

Most discussions of terraforming produced by philosophers are theoretical discussions. Some of the existing work on the ethics of terraforming takes the question as an opportunity to explore the implications of grand theories of ethics: what do utilitarianism, Kantianism, and virtue theory have to say when applied to this novel question of extraterrestrial ethics? More of the existing work takes the question as an opportunity to test, extend, or develop theories of intrinsic value-that is, theories that seek to sort entities that have value for their own sake from entities are only instrumentally valuable: what do anthropocentric, biocentric, ecocentric, and other theories of intrinsic value have to say about terraforming?

I will approach the question of the moral permissibility of terraforming Mars not as an opportunity to elaborate, test, or apply theories but rather as a question of practical ethics. Is terraforming Mars something we should do? We do not need to resort to theories to make progress in other, similarly practical ethical debates. Should terminal patients have the option of euthanasia? Is it wrong to farm animals for meat? Do corporations have moral obligations only to their shareholders? We can productively debate questions like these in the absence of consensus about the one true theory of ethics or intrinsic value. Mercifully so, since consensus around the one true theory of ethics is much harder to achieve than consensus around the ethics of meat-eating, corporate responsibility, or terraforming.

Instead of the theory-application method, I will throughout use the oldest and most universally accessible method of philosophical argument: I will identify beliefs I expect you already hold and argue from those beliefs to conclusions about terraforming. Since so much 
of the existing literature applies theories, I will not always faithfully report their original authors' reasoning. I will do my best to capture the spirit of theory-application arguments in practical terms that do not require the embrace of (or even the knowledge of) any particular philosophical theory. For readers interested in theory, I have included "references and further reading" notes at the end of each section. ${ }^{1}$

\subsection{Preservationist Arguments}

This section introduces three arguments for the conclusion that terraforming Mars is morally wrong. All three arguments seek to identify moral convictions that are clear-cut and uncontroversial on Earth, and simply extend them to Mars. The first argument focuses on the ethical treatment of objects of scientific interest, the second on the identification and ethical treatment of special wilderness areas, and the third on the attitudes and character traits we express when we undertake disruptive projects.

\subsubsection{We Should Preserve Mars's Value as a Unique Object of Scientific Interest}

Imagine that a team of scientists discovered an isolated island of surviving dinosaurs, as in Doyle's The Lost World. Imagine that these scientists are primarily interested in anatomy, so they euthanize the entire dinosaur population in order to preserve many specimens for comparative dissection. If this happened, it would go down in history as a heinous violation of scientific research ethics. The problem is not that dinosaur anatomy is uninteresting, or that dissection is an illegitimate research method. The problem (putting to one side, as is traditional, the animal welfare issue) is that there are many other scientific questions that a population of surviving dinosaurs could answer, and killing them forecloses them all. This hypothetical example illustrates one way scientists can act unethically in the pursuit of legitimate scientific questions: they act unethically if they treat an object of scientific interest in a way that makes the pursuit of other legitimate scientific questions impossible.

The same is true of real-world examples. If all goes well, NASA's OSIRIS-REx probe will return to Earth in 2023 carrying a payload of material sampled from asteroid Bennu. After the capsule is recovered, NASA will catalog, preserve, and store most of the sample so that future generations of scientists may study it [6.11]. Preserving the scientific value of this unique resource is, quite uncontroversially, the right thing to do.

Imagine that a scientist with huge institutional power at NASA decided to claim and destroy the entire OSIRIS-REx sample in an experiment that would significantly advance his own research program. No matter how interesting his research program, no matter how well designed his experiment, destroying that entire sample in pursuit of answers to his question would be morally wrong. It would be morally wrong because it would foreclose myriad other research programs, including those that haven't yet been imagined.

\footnotetext{
${ }^{1}$ References and further reading: James S.J. Schwartz critically reviews theory-application arguments about the ethics of terraforming, including all the theoretical arguments that I have adapted in this article; it is a good entry point into the theory-application literature [6.27]. For more on the advantages of avoiding the theory-application mode in practical debates about space ethics, see [6.20] [6.21] [6.36].
} 
This principle of scientific conservation, though rarely stated explicitly, is a principle most scientists observe in practice: methods of investigation of an object of scientific interest are morally permissible only when they do not foreclose the possibility of future investigations the threatened object could support.

As the most accessible planet in the solar system, and in several ways an analog of Earth, Mars is immensely valuable as an object of scientific study. The important questions we can hope to answer on Mars cluster around the fields of biology, climate evolution, and geologic/planetary evolution. Answers to these questions would reverberate well beyond their respective university departments. Evidence of past or current life on Mars would matter not just to biologists; it could change thinking in philosophy, theology, and in culture more generally. A better understanding of Mars's loss of most of its atmosphere and liquid water wouldn't merely provide insights for exo-climatologists; it could have implications for climate policy on Earth. A better understanding of Martian geology is a necessary condition of investigating its biological and climate history.

The planetary scale interventions proposed by terraformers would foreclose many lines of inquiry related to Mars's biological and climate history. Terraforming would seriously complicate, if not foreclose, many lines of inquiry into Martian geology. If we apply the same principle of scientific conservation to Mars as a scientific resource as we do to scientific resources on Earth, then terraforming is unambiguously ruled out. I do not doubt that terraforming "would generate a great wealth of new scientific and technical knowledge." Nor do I doubt that "Much of this information also would be relevant to understanding Earth's biosphere" [6.9, p. 139]. But answering legitimate scientific questions using methods that foreclose myriad other research programs, including those that haven't yet been imagined, is morally wrong. It is wrong on Earth and it would be wrong on Mars. ${ }^{2}$

\subsubsection{We Should Preserve the Integrity of the Martian Wilderness}

On Earth, we have little trouble acknowledging that at least some areas of wilderness should be preserved. The breadth of this consensus is evident in the popularity of preservationist projects, including wildlife refuges, protected wilderness areas, and national parks.

There are many ways to treat these protected areas wrongly. Hikers in the Boundary Waters Canoe Area Wilderness on the Minnesota/Ontario border would act wrongly were they to leave litter behind or dump their stove fuel there. Opportunists would act wrongly were they to poach animals or trees from it. Industry would act wrongly were it to use that land as a dumping ground for waste.

These destructive acts are not the only way to treat a wilderness wrongly. I opened this paper with the examples of White Sands National Park and Death Valley National Park. It would treat these deserts wrongly to irrigate them, import topsoil, and turn them into different and more lively biomes.

The ethical hiker's ideal is to "leave no trace." When we visit a relatively pristine wilderness, our goal should be to step lightly enough on it that our presence alters it only minimally. Leaving litter, dumping fuel, poaching trees, irrigating desert, importing topsoil,

\footnotetext{
${ }^{2}$ References and further reading: I have adapted the argument in this section from [6.36, Sec. 3]. Arguments in a similar spirit include [6.23] and [6.30]. See [6.31] for a robust account of the value of space science.
} 
are all examples of wrongful treatment of special wilderness areas because they are all instances of treading heavily upon them.

How, then, are we to decide which wilderness areas are those whose character as wilderness should be preserved? In a paper on the preservation of natural value, Holmes Rolston III proposed a set of six rules for identifying preservation-worthy wilderness areas anywhere in the solar system. Rolston's rules emerge from a dense theoretical discussion of nature and value, but at least three of his six rules articulate commonsensical criteria we already use to identify preservation-worthy wilderness areas on Earth. These three rules are entirely unmysterious and easily severable from Rolston's theoretical foundations.

- “Respect exotic extremes..." [6.25, p. 173]. Some wilderness areas distinguish themselves as unusual or unique in the natural world. Death Valley is exceptionally hot and Antarctica is exceptionally cold; the Great Barrier Reef is exceptionally biodiverse and the Atacama Desert exceptionally arid. All of these places have a claim to preservation in part because of their extremity.

- "Respect places of historical value" [6.25, p. 174]. Some wilderness areas distinguish themselves because of their historical importance to their region, country, or world. Yosemite Valley, for example, has a claim to preservation in part because of its historical importance to the development of American conservationist and preservationist movements.

- "Respect places of aesthetic value" [6.25, p. 177]. Some wilderness areas distinguish themselves because of their exceptional beauty. The Grand Canyon in Arizona, the Great Bear Rainforest in British Columbia, and Hawaii's Volcanoes National Park all have a claim to preservation in part because of their beauty.

The best-known wilderness areas on Earth achieve that status because they draw liberally on all three values: they are unusual, historically important, and beautiful. Such wildernesses should be preserved, and preserving them entails a moral obligation to tread lightly on them.

There are many regions of Mars that also draw liberally on all three values. Valles Marineris is a canyon an order of magnitude longer and wider than the Grand Canyon-possibly the largest canyon in the solar system. Gale crater and the landing sites of other robotic probes are sites of human heritage and history. The ghost dunes of Hellas Planitia are ancient stamps in the current landscape-historically important and visually striking. These and many other locations on Mars are extreme, historically important, and beautiful. If we simply extend the same principles that guide us in our efforts to preserve special wilderness on Earth, then many regions of Mars should be preserved. Terraforming the planet would tread heavily on all the special regions we ought to preserve. Treading heavily on preservation-worthy wilderness is wrong on Earth and it would be wrong on Mars.

I anticipate two objections to this argument; neither is compelling.

Objection 1: On Earth, there is energetic debate about how much wilderness we should protect and how much use of protected land is consistent with preserving its integrity as wilderness. This effort to balance wilderness preservation against other values is conspicuously 
absent from the wilderness-preservation argument against terraforming. The argument for preserving wilderness areas on Earth would not be plausible were it as totalizing and absolutist as this argument for the preservation of Mars.

Discussion: Terraforming would alter the entire planet. The temperature and atmospheric pressure increases which are the central goal of terraforming "would unavoidably flood the vast Marian lowlands, and the intensification of the water cycle would cause massive erosion in the highlands. Terraforming Mars would radically transform its landscapes and irreversibly change their aesthetic qualities" [6.19, p. 211].

The wilderness-preservation argument categorically rules out terraforming not because it lacks balance between wilderness preservation and other values but rather because terraforming's heavy tread is planet-wide by design.

Objection 2: An important background motivation for wilderness preservation on Earth is the fact that we like to visit these places. Since few or none of us will ever visit Valles Marineris, we have no reason to preserve it, even if it is extreme, beautiful, and historically important.

Discussion: I have already invited you to imagine an inhospitable wilderness you believe should be preserved. My opening example was the gypsum dunefield in White Sands. That dunefield is relatively inaccessible, I now live in Minnesota, and I am not confident I will visit White Sands again. But even if I were certain that I would never visit it again, that would not undermine my conviction that it should be preserved. I expect the same is true of your own beloved inhospitable wilderness. Our personal experiences with these places vivify our conviction that they should be preserved; the hope of future visits is not the reason why they should be preserved. It is simply a mistake to claim that the promise of a return to White Sands is a necessary condition of it being worthy of preservation, and it is similarly a mistake to believe that the promise of a trip to Valles Marieneris is a necessary condition of it being worthy of preservation. ${ }^{3}$

\subsubsection{We Should Avoid Expressing Colonialist Vices}

Many people, including many supporters of space programs, cringe at the colonialist language advocates of terraforming Mars sometimes use. For many people familiar with the history of colonialism on Earth, talk of expansion, resource exploitation, manifest destiny, and the settling of new worlds is, at least, badly out of tune. A number of the attitudes and character traits European colonists expressed toward the people and land they colonized were, in retrospect, obviously vices, and several of those vices echo in some advocacy for colonizing and terraforming Mars.

In retrospect, one vice vividly displayed during the phase of colonization and Westward expansion in North America was arrogance. Arrogance was certainly among the vices that motivated genocidal projects such as the boarding school movement, typified by the Carlisle Indian Industrial School, which was explicitly justified as an effort to "save" Native Americans from their own culture-a culture the school's organizers did not understand. Arrogance was among the vices that motivated ecologically disastrous efforts to eradicate keystone predators such as wolves, efforts undertaken by people with no understanding of

\footnotetext{
${ }^{3}$ References and further reading: I have adapted the argument in this section from [6.16] [6.19] [6.22] [6.25]
} [6.36, Sec. 4]. The pattern of argument I have used here is similar to [6.8, p. 234] [6.6]. 
the ecologies they sought to change. Colonialist arrogance in these cases is characterized by an attitude that, despite having little experience with the complex systems that comprised a new-to-them land, they understood it sufficiently well that they were justified in disrupting it.

A related colonialist vice was an inability to appreciate the distinctive beauty of unfamiliar things. Efforts to "civilize" Native Americans through programs like Indian boarding schools and forced adoption of Native children into White families were shameful in part because they so utterly failed to appreciate Native cultures on their own terms. An inability to appreciate the distinctive beauty of North American ecology motivated the introduction of invasive plants and animals that were familiar, and thus easier for colonialists to appreciate. People open to recognizing beauty in the unfamiliar would not have struggled to appreciate the distinctive beauty of North American biomes and indigenous cultures.

Mars certainly isn't home to intelligent creatures with ancient cultures. It probably isn't home to anything that could be characterized as a vigorous ecosystem, and it may house no life at all. Nevertheless, the attitudes of colonialist arrogance and insensitivity to distinctive beauty are readily detectable in much pro-terraforming talk. Elon Musk once described Mars as “a fixer-upper of a planet.” His repeated suggestion for jump-starting the terraforming process is to detonate nuclear bombs over the planet's poles-an idea he has sloganized and merchandised in the form of "Nuke Mars!" T-shirts [6.42]. It is hard not to hear echoes of colonialist vices of arrogance in the face of complexity and insensitivity to the distinctive beauty of an unfamiliar land. We are very far from understanding Mars's geological and weather processes; it is arrogant to believe we are justified in disrupting them. We have only minimal vicarious experience of the Martian wilderness; it almost certainly demonstrates insensitivity to its distinctive beauty to lament its lack of lakes and trees.

Arrogance and insensitivity were vices when they were expressed in the course of colonial projects on Earth. They are probably vices when expressed in colonial projects on Mars, too.

I anticipate an objection to this argument that has merit, though less as an objection than as a point of clarification.

Objection: Elon Musk and similar enthusiasts are not the only members of the proterraforming community; it is unfair to paint all terraformers with the brush of Musk's colonialist vices.

Discussion: It certainly is possible to imagine a terraforming project that bears no resemblance to Westward expansion in the methods it employs and the attitudes it expresses. It is possible to imagine those who advocate for Mars as a planetary refuge could acknowledge its beauty, stand in awe of its complexity, and still believe that we must attempt to terraform it in pursuit of even more important goals. We can imagine an approach to terraforming that begins from the conviction that this is a tragic project to be undertaken with regret, and that before we begin we must understand and preserve as much as we can of Mars.

All of this is true. The vice-expression argument against terraforming would not rule out terraforming projects that do not express vices. The vice-expression argument may be better understood as an argument for an obligation to reconfigure, possibly radically, our attitudes toward Mars. We should be appropriately humble in the face of Mars's complexity; we should learn to appreciate its distinctive beauty. Once our attitudes toward Mars no longer 
echo colonialist vices on Earth, then we can ask the question afresh: should we terraform Mars? The other preservationist arguments will still need to be overcome. ${ }^{4}$

\subsection{Interventionist Arguments}

This section introduces three arguments that terraforming Mars is something we ought to do. The first argument, closely associated with Robert Zubrin, appeals to a duty to fulfill our human nature. The second appeals to a duty to maximize the long-term survival chances of the human species. The third posits a moral obligation to restore a distinctively Martian ecosystem.

\subsubsection{We Should Fulfill our Inborn Nature as Pioneers}

For decades, Robert Zubrin has advocated-in exuberantly colonialist language-for the colonization and terraforming of Mars. For example: "Western humanist civilization as we know and value it today was born in expansion, grew in expansion, and can only exist in a dynamic expanding state. While some form of human society might persist in a nonexpanding world, that society will not foster freedom, creativity, individuality, or progress" [6.44, p. 332]. This view of human nature constitutes Zubrin's bedrock reason to terraform Mars: "I would say that failure to terraform Mars constitutes failure to live up to our human nature and a betrayal of our responsibility as members of the community of life itself" [6.44, p. 267].

Zubrin's case for colonizing and terraforming Mars is that the drive to expand is part of human nature, and therefore we have an obligation to do it. Although it is widespread thanks to Zubrin's advocacy, this argument has foundational problems; it should not persuade anyone of a moral obligation to terraform.

Objection 1: the lone premise of Zubrin's argument is probably false; it is far from clear that the drive to expand is part of human nature. Some people seem driven in this way, but many more are content to stay home. Why think the outward urge is part of human nature?

Objection 2: Even if we were to grant Zubrin's implausible premise, his argument faces an insurmountable problem: his inference from human nature to a recommendation for action is fallacious. Human nature is, after all, a many-splendored thing, and expansion isn't the only candidate for a natural human drive. We also apparently harbor drives "for revenge, war, sexual assault, scapegoating the socially marginalized, exploiting the downtrodden, denying the humanity of culturally unfamiliar people, stigmatizing disabled people, and arrogating to ourselves every kind of resource beyond all

\footnotetext{
${ }^{4}$ References and further reading: For early papers critical of colonialist language from space supporters, see [6.2] [6.13]. For a recent call for NASA to focus on eliminating the trappings of colonialism, see [6.41]. Thomas Hill wrote an early and influential paper arguing from virtues to environmental protections on Earth [6.10]. Robert Sparrow extends Hill's approach to Mars; he argues that terraforming instantiates vices of hubris and aesthetic insensitivity [6.34] [6.35]. Keekok Lee argues that our responses to nature everywhere should be characterized by attitudes of awe and humility, and that these attitudes are incompatible with terraforming Mars [6.12]. I have primarily drawn on Sparrow and Lee in adapting the argument in this section, though I have crudely separated their attitude-expression arguments from the theoretical foundations on which they build them.
} 
reason" [6.36, p. 338]. If these and others are drives we should not indulge, then Zubrin owes us an explanation of why expansion is a drive we have an obligation to indulge. His analogies to highly contested histories of American colonization and Westward expansion do not advance that goal. ${ }^{5}$

\subsubsection{We Should Increase Our Species' Chance of Long-Term Survival}

We know that the human species will one day slip into extinction, and many people plausibly believe we have a moral obligation to push that date as far into the future as we can. As it stands, though, our survival-in the short term, let alone the medium or long term-is not assured. At any point, we may face an extinction event: a lethal pandemic, an asteroid impact, global thermonuclear war, starvation due to resource depletion, or horrors as yet unimagined. One possible hedge against these disasters is to make ourselves a multi-planet species. Once our species is established and thriving on another planet, humanity will survive even if humans on Earth are wiped out.

In our solar system, Mars is the only plausible destination for a second viable human population. Even so, Mars, in its current state, is so inhospitable that it makes for a poor backup plan. If we want to improve the odds of long-term human survival, we will need to turn the surface of Mars into an environment that doesn't inevitably and swiftly kill humans. We should terraform Mars, therefore, as the best means of discharging our duty to extend the lifespan of our species.

Joseph Gottlieb recently argued that the species-survival argument for populating Mars overrides the kinds of preservationist arguments I surveyed in Section 6.3 of this paper. He argues via a series of analogies to more familiar terrestrial values. The analogy most relevant to terraforming and colonizing Mars is his third:

Suppose that a new pyramid is found by Giza in Egypt. It is, naturally enough, an object of immense scientific and archaeological curiosity. But suppose that, among its many valuable features, there lies deep within its structure, a vial of blue elixir locked in a sarcophagus. This elixir for whatever reason provides our best shot to cure cancer, but it will hinge on billions of dollars of future investment. Obtaining the vial will require many years of work and much financial investment, along with the destruction of the pyramid and all of its other contents. On top of this, the project is highly risky given its costs: there is only a 30 percent chance of success. That is, there is a 70 percent chance that we will destroy the pyramid and not get the elixir. [6.7, pp. 313-314]

A newly discovered pyramid is scientifically and aesthetically valuable; it is the sort of discovery we should treat with awe and humility. Nevertheless, if destroying the pyramid were our best shot to cure cancer, those values are overridden by the value of saving countless lives. The case of Mars is similar. We need not deny that Mars is scientifically and

\footnotetext{
${ }^{5}$ References and further reading: Robert Zubrin's The Case for Mars, especially its Epilogue, is the best source for his argument for the duty to settle and terraform Mars [6.44]. Every aspect of his argument has been roundly critiqued. For criticism of the claim that the drive to expand is part of human nature, see [6.28]. For criticism of Zubrin's (and others) endorsement of colonialist values and ideologies, see [6.2] [6.3]. For criticism of the analogy between Westward expansion and Mars settlement, see [6.13] [6.29].
} 
aesthetically valuable. But if the scientific and aesthetic value of a pyramid is overridden by the possibility of a cancer cure, then the scientific and aesthetic value of Mars is similarly overridden by the possibility of establishing a species-saving refuge.

A key advantage of Gottlieb's approach is that he does not deny the premises of preservationist arguments; instead, he argues that the conclusions of those arguments are simply overridden by a more important value. If Gottlieb's analogies succeed, then we have an obligation to colonize Mars despite our general obligation to conserve scientifically valuable resources, and to tread lightly on wilderness, and to avoid expressing the same vices as past colonialists.

Objection: My concern with Gottlieb's version of the species-preservation argument is that establishing a thriving human population on Mars is a long-shot, high-risk strategy for increasing the lifespan of our species. It is not yet clear that Mars can be terraformed, and even if it can it will take some time-give or take a few thousand years. It is not yet clear that humans can survive either the trip to Mars or the psychological rigors of confined life while the terraforming process unfolds. It is not yet clear that humans can survive and reproduce in Mars's low gravity-a challenge terraforming cannot address [6.39].

Meanwhile, there are many faster, cheaper, more reliable, and ethically unproblematic steps we can take to increase our chance of survival on Earth. These are a few pieces of low-hanging fruit: asteroid detection and redirection technology could reduce the chance of a species-threatening impact. Carbon capture and sequestration technology could take us off the path of runaway global warming. Next-generation vaccine research could eliminate the (already vanishingly small) chance of a 100\% infectious and $100 \%$ lethal pandemic. More effective international institutions and a more just approach to economic integration and global resource distribution could eliminate the chances of global thermonuclear war. All of these lines of research and development are cheaper and more reliably linked to the extension of our species' lifespan than terraforming and colonizing Mars. These are strategies that could yield protective fruit on a calendar scaled in decades, instead of colonization's centuries and terraforming's millennia. And these are strategies that do not incur the ethical costs of terraforming Mars.

A closer analogy than Gottlieb's pyramid, then, would be one in which we have two available avenues of research and development that promise a chance for a cancer cure. One is to destroy a newly discovered pyramid, which stands a small but real chance of yielding a cure for cancer a few centuries hence. The other is to pursue some breakthroughs in lab research that have emerged from the kind of careful lab work that has generated progress in the past. And, crucially, the ethically unproblematic lab-work path is more likely to succeed than the pyramid-destruction path, and to succeed sooner. In that case, I do not believe that destroying the pyramid would be morally permissible. Gottlieb's analogy is flawed because it stipulates that ethically costly pyramid-destruction is our best shot for a cancer cure, when the ethically costly strategy of expanding to Mars is probably not our best shot for our species' survival.

Discussion: The debate about the species-survival argument turns in part on predictions about what existential threats we are likely to face and empirical claims about what preparations are likely to avert them. Depending on what we learn in the future-about Mars, and Earth, and the threats we face-my objection to the species-survival argument may grow weaker or stronger. 
The inherent uncertainty of prediction opens the door to a much worse version of the species-survival argument than the version Gottlieb defends. I would like briefly to discuss the worse version of the argument because it reliably comes up in discussions and classroom debates about the ethics of terraforming.

The worse version of the species-survival argument develops along these lines. Imagine a future scenario in which human life on Earth is destroyed by a threat we prove unable to divert with Earth-based solutions. In that scenario, if we had already established a thriving human population on a successfully terraformed Mars, not all would be lost. Those surviving humans would undoubtedly insist that terraforming Mars had been the right thing to do, and we, today, can see that those future people would be right. That terraforming Mars is so clearly the right thing to do in that imaginary scenario-says the terraforming advocate-is enough to establish that terraforming Mars is the right thing to do, full-stop.

This form of argument, which moves from an unlikely speculative scenario to a recommendation for real-world actions or policies, is dangerously unreliable and should never be trusted. We can imagine unlikely speculative scenarios in which virtually any course of action averts disaster and leads to grand outcomes; that establishes exactly nothing about the real-world effectiveness (or the moral permissibility) of that course of action.

For example, in the shadow of $9 / 11$, many people were swayed by ticking-bomb arguments to accept that governments should torture suspected terrorists in an effort to prevent attacks. These arguments begin by inviting us to imagine a situation in which torturing a suspect is the only way to gather information that will allow government agents to defuse a ticking bomb, thus saving 10,000 innocent lives. In that scenario, torturing the terrorist to save innocent lives is the right thing to do, and banning torture would be a disaster. That torture should be available to government agents in that ticking-bomb scenario-says the torture advocate-is enough to establish that torture should be available to government agents, full-stop.

It is in retrospect shameful that anyone was persuaded by this nonsense. A ticking-bomb scenario is unlikely to come to pass; we rarely know who planted the bomb, interrogations virtually never happen under those time-pressured circumstances, torture is as likely to extract lies as truth, torture has real-world ripple effects ignored in the ticking-bomb scenario, and so on. There is no reason at all to think that the right policy for the unlikely imaginary scenario is the right policy for the real world. We should generalize this lesson, and dismiss any argument that derives policies or prescriptions for action from speculative scenarios that are unlikely to come to pass. The worse version of the species-survival argument for terraforming makes that mistake; it employs a pattern of reasoning that can justify literally anything, including terrible crimes.

Summary: the species-preservation argument holds that we have a duty to extend the lifespan of our species, and that this duty entails a duty to terraform Mars that overrides the preservationist duties I summarized in Section 6.3. I am unpersuaded by the speciessurvival argument. If it is interpreted as a cost/benefit assertion that we have an overriding duty to terraform because that is our best shot to extend the life-span of our species, it appears to rely on a false premise-there are better shots that don't incur terraforming's ethical costs. Interpreted as an argument from an imaginary scenario in which terraforming 
saves our species to the conclusion that we should terraform, it relies on a dangerously fallacious pattern of reasoning. ${ }^{6}$

\subsubsection{We Should Rehabilitate Mars for Martians}

The possible existence of indigenous Martian microbes has long been a focus of the debate about the appropriate human uses of Mars. Were we to discover life on Mars, many people share Carl Sagan's conviction: "If there is life on Mars, I believe we should do nothing with Mars. Mars then belongs to the Martians, even if the Martians are only microbes. The existence of an independent biology on a nearby planet is a treasure beyond assessing, and the preservation of that life must, I think, supersede any other possible use of Mars" [6.26, p. 130].

The preservationist arguments surveyed in Section 6.3 of this paper support Sagan's conviction. Life on Mars would immeasurably increase Mars's already immense scientific value. If microbes populate the Martian wilderness, then that wilderness harbors additional layers of complexity that we should be careful not to trample. If Mars's geological and weather systems embrace life systems, then the call to cultivate attitudes of humility and appreciation rings even clearer.

However, the discovery of indigenous Martian life would also make available what I believe to be the most thought-provoking and plausible argument in favor of intervening in the Martian climate. If there is Martian life on Mars, it is tightly constrained by a hostile environment; "it is not doing well" [6.17, p. 4]. We have strong evidence that Mars was previously a more welcoming planet than it is now, with liquid water and a thicker atmosphere. If life survives on Mars, it may be the ragged remnant of life that once thrived under more hospitable conditions. In that case, if we can restore Mars's earlier climate, and encourage the restoration of its earlier ecosystems, then perhaps we should.

Consider terrestrial analogies of ecosystems threatened by an external shock. When we recognize that a potentially invasive species poses a novel threat to an ecosystem, we should take steps to prevent it from taking root. Preventing the destruction of ecosystems, when reasonably possible, is something we should do, even when we are not the source of the threat.

More fancifully, imagine extraterrestrials in Earth orbit 10 million years ago. They note Earth's unique biosphere, teeming with organisms that exist nowhere else in the universe. And then they notice an enormous asteroid hurtling toward the planet, which will destroy all life on it. If they have the ability to direct the asteroid away from impact, they probably

\footnotetext{
${ }^{6}$ References and further reading: Elon Musk is a celebrity endorser of the species-survival argument for establishing a minimum viable human population on Mars [6.24]; Charles Cockell surveys some of the reasons a colony on an un-terraformed Mars is unlikely to thrive [6.4]. Molly Macauley [6.15], Joseph Gottlieb [6.7] and Szocik, Norman and Reiss [6.40] argue that the duty to preserve the species overrides the preservationist arguments surveyed in Section 6.3 of this paper. Paul York engages the better version of the species-preservation argument, arguing that there are very few scenarios in which terraforming Mars would extend humanity's lifespan [6.43]. I argue that there are more effective hedges against existential risk than Mars colonies [6.36, Sec. 2.4]. For a more detailed methodological criticism of the worse version of the species-preservation argument, see [6.37, Sec. 2.1] [6.38, Sec. 3.1]. My discussion of ticking-bomb arguments draws on Henry Shue [6.32].
} 
should. A genuine and appropriate appreciation of Earth's unique lifeforms is prima facie incompatible with standing idly by and watching it destroyed.

The duty to act to protect an ecosystem from external shocks, when that is possible, may well extend to a duty to restore ecosystems when they have been damaged. Imagine, for example, a thriving, unique wetland ecosystem that drains after a small earthquake. If we have the ability to seal the fissure and restore that ecosystem, its biodiversity, its mutually interdependent life, we probably should. Appropriate appreciation of that unique ecosystem is prima facie incompatible with standing idly by when we could act to restore it.

These cases suggest that it is at least morally permissible to intervene to preserve or restore the balance of an ecosystem threatened or damaged by some external shock. If Mars has indigenous life, then it may be an ecosystem we should try to restore via planetary-scale interventions in its climate.

Discussion: this is an argument not for terraforming Mars, but rather for restoring a distinctively Martian climate that may remain inhospitable to humans. An argument that advocates for planetary scale climate intervention for the sake of Martians has this significant advantage over terraforming proposals that aim to modify Mars for humans: it is not obviously open to the preservationist objections surveyed in Section 6.3. A restorationist project could only hope to succeed after a long period of rigorous scientific investigation. It could not begin so long as there were important open questions that climate intervention would foreclose. A prudent restorationist program, then, would not violate the principle of scientific conservation. As a wilderness restoration project, not a wilderness disruption project, it may not violate our duty to preserve wilderness areas. And it would express a starkly different set of attitudes toward Mars than the arrogance and aesthetic insensitivity that have characterized past colonial projects. ${ }^{7}$

\subsection{Conclusion}

I have surveyed six of the most prominent arguments about the ethics of terraforming Mars. Of the six, it seems to me that the argument from scientific conservation (Section 6.3.1) is the most ecumenical. Nearly everyone who can claim even a slight interest in terraforming recognizes the scientific value of Mars and acknowledges, in action if not speech, the plausibility of the principle of scientific conservation. I worry that it is the mind-boggling scale of terraforming proposals that causes some advocates to overlook the scientific value of a pristine Mars. We do and we should go to significantly more trouble to protect vastly less valuable scientific resources than the planet Mars.

The best-known arguments on the interventionist side-Zubrin-style appeal to human nature (Section 6.4.1) and Musk-style appeal to human survival (Section 6.4.2) - have been extensively criticized. Christopher McKay's argument for restoring a distinctively Martian ecology (Section 6.4.3) has received less critical attention. It offers a novel justification for changing Mars's climate that avoids the worst excesses of other arguments for terraforming. It is notable, though, that McKay's vision of Martian ecopoiesis-done for the good of

\footnotetext{
${ }^{7}$ References and further reading: For discussion of Sagan's position that preserving Martian microbes is a moral imperative, see [6.5] [6.14] (supportive) and [6.33] (opposed). I have adapted the argument in this section from [6.17] [6.18].
} 
Martian microbes, after sufficient research reveals how to accomplish that goal-bears little resemblance to terraforming as it is usually conceived.

When it comes to the ethics of terraforming as terraforming is usually conceived, the weight of argument appears to me to tilt sharply to the preservationist side. Preservationists have offered several arguments motivated by the conviction that we should extend to Mars the same moral principles we embrace on Earth. Those arguments are plausible on their face and have not received significant critical engagement from interventionists. Arguments in favor of terraforming, on the other hand, have been engaged by critics and have clear weaknesses.

One reason for this asymmetry may be historical. The arguments in favor of terraforming Mars have been in place for decades and are repeated in popular culture-there has been time to critically evaluate them. Objections to terraforming that are not rooted in a systematic theory of ethics or intrinsic value are newer and less prominent. Perhaps there are flaws in the arguments from scientific conservation, wilderness preservation, and attitude expression, and they simply haven't had the time to come to light. But until compelling objections to preservationist arguments emerge, I provisionally conclude that terraforming Mars is morally wrong. Even if we could do it, we shouldn't.

\section{Acknowledgments}

I am grateful for feedback from Crystal Bergstrom, Joseph Gottlieb, James S.J. Schwartz, Mark Stoner, and Jason Swartwood.

\section{References}

[6.1] Astrobiology Magazine, Should We Terraform? Astrobiology Magazine June 16th, 2004, https://www.astrobio.net/mars/should-we-terraform/ [2 December 2020].

[6.2] Billings, L., Frontier Days in Space: Are They Over? Space Policy, 13, 3, 187-190, 1997, https://doi.org/10.1016/S0265-9646(97)00020-9.

[6.3] Billings, L., Should Humans Colonize Other Planets? No. Theol. Sci., 15, 3, 321-332, 2017, https://doi.org/10.1080/14746700.2017.1335065.

[6.4] Cockell, C., Mars Is an Awful Place to Live. Interdiscip. Sci. Rev., 27, 1, 32-38, 2002, https:// doi.org/10.1179/030801802225002881.

[6.5] Cockell, C., The Ethical Status of Microbial Life on Earth and Elsewhere: In Defence of Intrinsic Value, in: The Ethics of Space Exploration, J.S.J. Schwartz and T. Milligan (Eds.), pp. 167-179, Springer, New York, 2016, https://doi.org/10.1007/978-3-319-39827-3_12.

[6.6] Cockell, C. and Horneck, G., Planetary Parks-Formulating a Wilderness Policy for Planetary Bodies. Space Policy, 22, 4, 256-261, 2006, https://doi.org/10.1016/j.spacepol.2006.08.006.

[6.7] Gottlieb, J., Space Colonization and Existential Risk. J. Am. Philos. Assoc., 5, 3, 306-320, 2019, https://doi.org/10.1017/apa.2019.12.

[6.8] Hartmann, W., Space Exploration and Environmental Issues. Environ. Ethics, 6, 3, 227-239, 1984, https://doi.org/10.5840/enviroethics19846325.

[6.9] Haynes, R.H. and McKay, C.P., The Implantation of Life on Mars: Feasibility and Motivation. Adv. Space Res., 12, 4, 133-140, 1992, https://doi.org/10.1016/0273-1177(92)90167-V. 
[6.10] Hill, T., Ideals of Human Excellence and Preserving Natural Environments. Environ. Ethics, 5, 3, 211-224, 1983, https://doi.org/10.5840/enviroethics19835327.

[6.11] Hille, K., OSIRIS-REx Mission Operations, NASA, 2016, http://www.nasa.gov/content/ osiris-rex-mission-operations [2 December 2020].

[6.12] Lee, K., Awe and Humility: Intrinsic Value in Nature. Beyond an Earthbound Environmental Ethics. R. Inst. Philos. Suppl., 36, 89-101, 1994, https://doi.org/10.1017/S1358246100006470.

[6.13] Limerick, P., Imagined Frontiers: Westward Expansion and the Future of the Space Program, in: Space Policy Alternatives, R. Byerly (Ed.), pp. 249-262, Westview Press, Boulder, 1992.

[6.14] Lupisella, M., The Rights of Martians. Space Policy, 13, 2, 89-94, 1997, https://doi. org/10.1016/S0265-9646(97)00009-X.

[6.15] Macauley, M.K., Environmentally Sustainable Human Space Activities: Can Challenges of Planetary Protection be Reconciled? Astropolitics, 5, 3, 209-236, 2007, https://doi. org/10.1080/14777620701662345.

[6.16] Matthews, J. and McMahon, S., Exogeoconservation: Protecting geological heritage on celestialbodies. Acta Astronaut., 149, 55-60, 2018, https://doi.org/10.1016/j.actaastro.2018.05.034.

[6.17] McKay, C., Let's Put Martian Life First. Planet. Rep., July/August, 4-5, 2001.

[6.18] McKay, C., Planetary Ecosynthesis on Mars: Restoration Ecology and Environmental Ethics, in: Exploring the Origin, Extent, and Future of Life: Philosophical, Ethical and Theological Perspectives, C.M. Bertka (Ed.), pp. 245-260, Cambridge University Press, Cambridge, 2009.

[6.19] McMahon, S., The Aesthetic Objection to Terraforming Mars, in: The Ethics of Space Exploration, Schwartz and Milligan (Eds.), pp. 209-218, Springer, New York, 2016, https:// doi.org/10.1007/978-3-319-39827-3_15.

[6.20] Milligan, T., Space Ethics Without Foundations, in: The Ethics of Space Exploration, Schwartz and Milligan (Eds.), pp. 125-134, Springer, New York, 2016, https://doi.org/10.1007/ 978-3-319-39827-3_9.

[6.21] Milligan, T., Basic Methodology for Space Ethics, in: Into Space - A Journey of How Humans Adapt and Live in Microgravity, T. Russomano and L. Rehnberg (Eds.), IntechOpen, London, 2018, https://doi.org/10.5772/intechopen.75689.

[6.22] Milligan, T., Valuing Humans and Valuing Places: "Integrity" and the Preferred Terminology for Geoethics. Geosciences, 8, 1, 25, 2018, https://doi.org/10.3390/geosciences8010025.

[6.23] Munévar, G., Science and Ethics in the Exploration of Mars, in: The Human Factor in a Mission to Mars: An Interdisciplinary Approach, K. Szocik (Ed.), pp. 185-200, Springer, New York, 2019, https://doi.org/10.1007/978-3-030-02059-0_11.

[6.24] Musk, E., Making Humans a Multi-Planetary Species. New Space, 5, 2, 46-61, 2017, https:// doi.org/10.1089/space.2017.29009.emu.

[6.25] Rolston, H., The Preservation of Natural Value in the Solar System, in: Beyond Spaceship Earth: Environmental Ethics and the Solar System, E. Hargrove (Ed.), pp. 140-182, Sierra Club Books, San Francisco, 1986.

[6.26] Sagan, C., Cosmos, Ballantine Books, New York, 1980.

[6.27] Schwartz, J.S.J., On the Moral Permissibility of Terraforming. Ethics Environ., 18, 2, 1-31, 2013, https://doi.org/10.2979/ethicsenviro.18.2.1.

[6.28] Schwartz, J.S.J., Myth-Free Space Advocacy Part I: The Myth of Innate Exploratory and Migratory Urges. Acta Astronaut., 137, 450-460, 2017, https://doi.org/10.1016/j. actaastro.2017.05.002.

[6.29] Schwartz, J.S.J., Myth-Free Space Advocacy Part II: The Myth of the Space Frontier. Astropolitics, 15, 2, 167-184, 2017, https://doi.org/10.1080/14777622.2017.1339255.

[6.30] Schwartz, J.S.J., Mars: Science Before Settlement. Theol. Sci., 17, 3, 324-331, 2019, https:// doi.org/10.1080/14746700.2019.1632520. 
[6.31] Schwartz, J.S.J., The Value of Science in Space Exploration, Oxford University Press, New York, 2020.

[6.32] Shue, H., Torture in Dreamland: Disposing of the Ticking Bomb. Case West. Reserve J. Int. Law, 37, 231, 2005.

[6.33] Smith, K., The Curious Case of the Martian Microbes: Mariomania, Intrinsic Value and the Prime Directive, in: The Ethics of Space Exploration, J.S.J. Schwartz and T. Milligan (Eds.), pp. 195-208, Springer, New York, 2016, https://doi.org/10.1007/978-3-319-39827-3_14.

[6.34] Sparrow, R., The Ethics of Terraforming. Environ. Ethics, 21, 3, 227-245, 1999, https://doi. org/10.5840/enviroethics199921315.

[6.35] Sparrow, R., Terraforming, Vandalism, and Virtue Ethics, in: Commercial space exploration: Ethics, policy and governance, J. Galliott (Ed.), pp. 161-178, Routledge, New York, 2015.

[6.36] Stoner, I., Humans Should Not Colonize Mars. J. Am. Philos. Assoc., 3, 3, 334-353, 2017, https://doi.org/10.1017/apa.2017.26.

[6.37] Stoner, I., Stable Strategies for Personal Development: On the Prudential Value of Radical Enhancement and the Philosophical Value of Speculative Fiction. Metaphilosophy, 51, 1, 128-150, 2020, https://doi.org/10.1111/meta.12404.

[6.38] Stoner, I. and Swartwood, J., Fanciful Examples. Metaphilosophy, 48, 3, 325-344, 2017, https://doi.org/10.1111/meta.12234.

[6.39] Szocik, K., Marques, R.E., Abood, S., Kędzior, A., Lysenko-Ryba, K., Minich, D., Biological and social challenges of human reproduction in a long-term Mars base. Futures, 100, 56-62, 2018, https://doi.org/10.1016/j.futures.2018.04.006.

[6.40] Szocik, K., Norman, Z., Reiss, M.J., Ethical Challenges in Human Space Missions: A Space Refuge, Scientific Value, and Human Gene Editing for Space. Sci. Eng. Ethics, 26, 3, 1209 1227, 2020, https://doi.org/10.1007/s11948-019-00131-1.

[6.41] Tavares, F., Buckner, D., Burton, D., McKaig, J., Prem, P., Ravanis, E., Trevino, N., Venkatesan, A., Vance, S., Vidaurri, M., Walkowicz, L., Wilhelm, M.B., Ethical Exploration and the Role of Planetary Protection in Disrupting Colonial Practices, 2020, White paper available at http://arxiv.org/abs/2010.08344 [2 December 2020]. See also this volume.

[6.42] Wall, M., Elon Musk Floats 'Nuke Mars' Idea Again (He Has T-Shirts), Space.com, 2019, August 17, https://www.space.com/elon-musk-nuke-mars-terraforming.html [2 December 2020].

[6.43] York, P.F., The Ethics of Terraforming. Philosophy Now, 38, 6-9, 2002.

[6.44] Zubrin, R. and Wagner, R., The Case for Mars: The Plan to Settle the Red Planet and Why We Must, Simon and Schuster, New York, 2011. 